\title{
KARAKTERISTIK LAMA MASAK DAN WARNA PEMPEK INSTAN DENGAN METODE FREEZE DRYING
}

Characteristics of Cooking Length and Colour of Instant Pempek with Freeze Drying Methods

\author{
A. Alhanannasir ${ }^{1) *}$, Amin Rejo $^{2)}$, Daniel Saputra $^{2)}$, Gatot Priyanto ${ }^{2)}$ \\ ${ }^{1)}$ Prodi Ilmu dan Teknologi Pangan, Fakultas Pertanian, Universitas Muhammadiyah Palembang \\ Jalan Jend. A. Yani 13 Ulu Palembang \\ *E-mail: nasiralhanan@ gmail.com \\ ${ }^{2)}$ Prodi Teknologi Hasil Pertanian Fakultas Pertanian Universitas Sriwijaya \\ Jalan Palembang-Indralaya Kab. Ogan Ilir Sumatera Selatan
}

\begin{abstract}
Pempek is a typical food of Palembang, South Sumatra, Indonesia, mostly processed in the form of wet with a moisture content of 50-60\%, so that it only lasts for 3-4 days. In order for pempek to long last, it was processed into instant pempek using the freeze drying method. Pempek had tube form with a size of $3 \mathrm{~cm}$ in high and $4 \mathrm{~cm}$ in diameter. This study was aimed to see the freeze drying pressure and time to length of cooking, density, and lightness of instant pempek. Stored pempek at temperature of $-50^{\circ} \mathrm{C}$ was carried out freeze drying with a pressure of 0.002 bar, 004 bar, 0.006 bar, and 0.008 bar for 38 hours, 40 hours, 42 hours, and 44 hours with a methodology of Split the Duncan Real Distance Difference Test Plot Design. The result showed that the pressure and time had very significant effect on the length of cooking, density and lightness of pempek. P3 (0.006 bar) pressure treatment affected shorter cooking time of pempek about 10.83 minutes, L2 treatment has 14.17 minutes for cooking times and the P3L2 treatment combination has low density of $0.71 \mathrm{~g} / \mathrm{cm} 3$ and color brightness (lightness) about 85.38, almost resemble with white color. Making instant pempek with freeze drying method gave better results in ways of shorter and faster cooking time than instant pempek by other drying methods.
\end{abstract}

Keywords: cooking length, freeze drying, instant pempek

\section{PENDAHULUAN}

Makanan basah atau semi basah yang mengalami proses pengeringan akan terjadi fenomena transfer secara simultan yaitu terjadi transfer panas dan transfer massa air. Panas akan ditransfer ke bahan makanan dan massa air akan diuapkan dari bahan makanan sehingga akan didapat makanan kering atau instan. Pengeringan makanan bertujuan untuk menurunkan aktivitas air $\left(\mathrm{a}_{\mathrm{w}}\right)$, menambah daya simpan menjadi lebih lama, tidak mudah mengalami kerusakan, dan biaya transportasi murah karena massa bahan rendah. Aktivitas air sangat penting untuk melihat umur simpan makanan karena dapat mengendalikan dan menekan pertumbuhan mikroorganisme, mengurangi adanya reaksi kimia, dan menghambat kerusakan oleh enzim-enzim (Bonazzi et al., 2011).

Pempek yang diolah masih banyak dalam bentuk basah atau semi basah, sehingga pempek tidak tahan lama, dan masih sedikit sekali dalam bentuk kering atau instan. Ada beberapa jenis atau bentuk pempek di antaranya berbentuk lenjeran besar panjang, lenjeran kecil pendek, kapal selam, adaan, otak-otak, pempek keriting dan pastel. Pempek basah atau semi basah merupakan makanan yang akan mudah mengalami kerusakan dan memiliki waktu simpan yang pendek. Pempek lenjer yang disimpan pada suhu ruang $\left(25^{\circ} \mathrm{C}\right)$ memiliki umur simpan selama 27-33 jam (Karneta et al., 2013). Pempek semi basah dapat dijadikan pempek instan. Pempek instan harus 
diupayakan dapat dengan mudah mengalami rehidrasi dalam waktu relatif singkat agar pempek tersebut segera dapat dikonsumsi.

Alat pengeringan yang digunakan untuk pengeringan bahan pangan ada beberapa macam. Khalloufi et al. (2012) menyatakan pengeringan wortel dengan cara freeze drying memiliki pori-pori lebih besar (0.8-1.0) bila dibandingan dengan cara pengeringan air drying (0.12-0.14). Madiouli et al. (2012) menyatakan pengeringan dengan menggunakan suhu $35^{\circ} \mathrm{C}$ pada tekanan 0.004 bar akan menghasilkan pori-pori apel $90 \%$, sedangkan wortel, kentang dan pisang sebesar 80-85\%. Koc et al. (2008) menyatakan pengeringan pangan fresh quinces ukuran $11 \times 11 \times 11 \mathrm{~mm}^{3}$ dengan freeze drying yang diawali dengan pembekuan pada suhu $-25^{\circ} \mathrm{C}$, kemudian dimasukkan dalam freeze drying dengan tekanan 0.0014 bar pada suhu kondensor $50^{\circ} \mathrm{C}$. Dari penelitian ini diperoleh poriporinya 0.7-0.8 lebih tinggi bila dibandingkandengan cara fluid bed drying, tray drying, dan infrared drying. Alhanannasir et al. (2017) menyatakan bahwa pengeringan makanan dengan menggunakan cara dan jenis alat pengering akan menentukan lama waktu masaknya. Penelitian dengan menggunakan oven diperoleh bahwa lama waktu masaknya yaitu 22,09 menit.

Ratti et al. (2013) menyatakan bahwa pembuatan tepung powder dengan menggunakan freeze drying dengan suhu di bawah titik tripel dan tekanan dibawah $612 \mathrm{~Pa}$ agar mudah mengalami sublimasi. Buah kiwi dikeringkan dengan menggunakan freeze drying pada suhu $-40^{\circ}$ $\mathrm{C}$, namun sebelumnya buah kiwi harus dibekukan terlebih dahulu. Pembekuan dapat dilakukan dengan cepat atau lambat, pembekuan cepat pada suhu $-40^{\circ} \mathrm{C}$, sedangkan pembekuan lambat pada suhu $24^{\circ} \mathrm{C}$. Produk beku yang dimasukkan dalam ruangan vakum agar terjadi sublimasi dengan menjaga ruangan tetap vakum pada tekanan sebesar $610.5 \mathrm{~Pa}$ atau 0.006105 bar.

Metode pengeringan menggunakan freeze drying mampu mengurangi kandungan air bahan sehingga membuat pangan menjadi lebih awet. Pempek semi basah dapat dijadikan pempek instan melalui pengeringan dengan metode freeze drying. Penelitian ini menentukan tekanan dan waktu freeze drying terhadap lama masak, densitas, dan lightness (kecerahan warna) pempek instan.

Bahan-bahan penelitian yang digunakan untuk pembuatan pempek instan adalah dari ikan gabus dan tepung tapioka sehingga menjadi pempek instan dialakukan dengan metode freeze drying diawali dengan pembekuan. Penelitian ini bertujuan untuk menentukan tekanan dan waktu freeze drying terhadap lama masak, densitas, dan lightness pempek instan

\section{METODE PENELITIAN}

\section{Alat dan Bahan}

Bahan-bahan terdiri dari ikan gabus giling, tepung tapioka, garam halus, dan air dan bahan-bahan analisis kimia. Alatalat yang digunakan meliputi pengering beku (freeze drying) (merk snijders scientific), colour reader CR-300 (merk Minolt), jangka sorong (merk Kincromec Digital Vernier Caliper), mistar, timbangan digital, plastik atau kantong plastik jernih, sendok makan, sendok teh, pisau, bak atau baskom plastik, mesin penggiling ikan, panci stainless steel, pengaduk, kompor gas, rak-rak plastik.

\section{Tahapan Penelitian}

Pembuatan Pempek

Pempek instan dibuat dari bahan berupa ikan gabus giling, tepung tapioka, garam halus, dan air yang diperoleh di pasar-pasar lokal di kota Palembang, Sumatera Selatan, Indonesia. Tepung tapioka ditimbang sebanyak $450 \mathrm{~g}$, daging ikan gabus giling sebanyak $550 \mathrm{~g}$, dan garam sebanyak 2,5\% (11,25 g) dari berat 
tepung tapioka. Air disiapkan sebanyak $50 \%(225 \mathrm{ml})$ dari berat tepung tapioka. Daging ikan gabus giling, garam dan air dilakukan pencampuran secara merata sebagai adonan 1. Adonan 1 ditambahkan tepung tapioka sedikit demi sedikit sambil diaduk pelan-pelan hingga merata dan bahan bisa dibentuk sebagai adonan 2 . Adonan 2 ditimbang seberat $300 \mathrm{~g}$, lalu dibentuk lenjeran dengan diameter $4 \mathrm{~cm}$ dan panjang $20 \mathrm{~cm}$. Pemasakan dilakukan dengan cara perebusan selama 20 menit hingga matang atau ditandai pempek mengapung. Diangkat dan ditiriskan, dan dilakukan pemotongan sampel dengan ukuran panjang atau tinggi $3 \mathrm{~cm}$.

\section{Proses Freeze Drying pada Pempek}

Sampel pempek dimasukkan ke dalam chamber. Pempek dalam chamber dimasukkan ke dalam freezer (pembeku) dengan suhu $-20^{\circ} \mathrm{C}$ selama 48 jam. Freeze dryer dinyalakan sampai suhu $-50^{\circ} \mathrm{C}$ selama 2 jam. Chamber dihubungkan ke karet freeze dryer. Vacum dinyalakan dan kran freeze dryer dibuka. Dilakukan pengaturan variasi tekanan $(\mathrm{P})$ dan waktu (L) pengeringan selama proses freeze drying sampai diperoleh pempek instan.

\section{Rancangan Percobaan}

Rancangan percobaan yang digunakan adalah Rancangan Acak Petak Terbagi (Split Plot Design) disusun secara faktorial dengan faktor petak utama (main plot) yaitu tekanan (P) dan sebagai anak petaknya adalah lama waktu dalam freeze drying (L) yang diulang sebanyak 3 kali. Adapun perlakuan menurut kelompok, tekanan dan waktu pengeringan. Variasi pemberian tekanan dan waktu/lama pengeringan pada proses freeze drying pempek meliputi perlakuan tekanan sebagai petak utama (main plot) yaitu tekanan 0,002 bar (P1), tekanan 0,004 bar (P2), tekanan 0,006 bar (P3), tekanan 0,008 bar (P4), dan tingkat faktor perlakuan lama waktu dalam freeze drying sebagai anak petak (sub plot) yaitu waktu
38 jam (L1), waktu 40 jam (L2), waktu 42 jam (L3), waktu 44 jam (L4) dan kombinasi perlakuan keduanya (PL).

\section{Metode Analisis}

Pengukuran Lama Masak (Alhanannasir, 2017)

Lama waktu masak dalam satuan menit yaitu dilakukan pengukuran lama waktu mulai melakukan perebusan pada air yang telah mendidih pada suhu $100^{\circ} \mathrm{C}$ sampai pempek matang atau masak. Rumus pengukuran lama masak yaitu:

$$
\mathrm{T}_{\mathrm{m}}=\mathrm{T}_{2}-\mathrm{T}_{1}
$$

Keterangan:

$\mathrm{T}_{\mathrm{m}}=$ Lama waktu masak

$\mathrm{T}_{1}=$ Waktu awal perebusan

$\mathrm{T}_{2}=$ Waktu akhir perebusan

Pengukuran Densitas (Liu et al., 2012 dan Madiouli et al., 2012)

Densitas atau massa jenis adalah suatu besaran kerapatan massa benda yang dinyatakan dalam berat benda per satuan volume benda dalam satuan $\mathrm{kg} / \mathrm{m}^{3}$ atau $\mathrm{g} / \mathrm{cm}^{3}$. Pengukuran densitas selain berdasarkan formula dari Liu et al. (2012), dan Madiouli et al. (2012), juga menggunakan formula dari Zogzas et al. (1994), Krokida et al. (1997 dan 2000), Koc et al. (2008), Martynenko (2008), Khalloufi et al. (2009), dan Mayor et al. (2011) yaitu perbandingan massa benda (m) dengan volume $\left(\mathrm{cm}^{3}\right)$. Adapun untuk menghitung densitas diseuaikan dengan bendanya yang dapat dilakukan menghitung dengan menggunakan rumus:

$$
\rho=\frac{\mathrm{m}}{\mathrm{v}}
$$

Keterangan:

$\rho=$ massa jenis atau densitas $\left(\mathrm{g} / \mathrm{cm}^{3}\right)$

$\mathrm{m}=$ massa benda $(\mathrm{g})$

$\mathrm{v}=$ volume $\left(\mathrm{cm}^{3}\right)$ 
Pengukuran Warna (deMan, 1999)

Warna pempek lenjer instan diukur dengan menggunakan Colour Reader CR300. Colour reader dinyalakan dan tombol fungsi diaktifkan untuk memilih dan menentukan nilai dan angka yang digunakan, tekan tombol calibarate (warna kuning), tetapkan kondisi $\mathrm{a}^{*}$ dan $\mathrm{b}^{*}$ harus nol dan L (lightness) $=100$, sampel dimasukkan ke dalam wadah transparan (plastik bening/blanko), posisikan penembak warna (colour reader) di atas blanko, tekan measure sekali dan tunggu sampai terpotret $3 \mathrm{kali}$, tempelkan sampel ke alat pemotret dan akan muncul angka $\mathrm{L}(\%), \mathrm{H}\left({ }^{\circ}\right)$, dan $\mathrm{C}(\%)$ yang tertera pada alat dan dilakukan pencatatan.

\section{HASIL DAN PEMBAHASAN}

\section{Lama Masak Pempek Instan}

Waktu lama masak adalah waktu yang dibutuhkan mengembalikan pempek instan ke bentuk pempek semi basah. Perebusan pempek dilakukan pada air mendidih (suhu $100^{\circ} \mathrm{C}$ ). Hasil analisis keragaman lama masak diperoleh bahwa perlakuan tekanan, dan waktu memberikan pengaruh yang sangat nyata terhadap waktu masak (cooking time) pempek lenjer instan, tetapi perlakuan interaksi memberikan pengaruh yang tidak nyata terhadap pempek lenjer instan.

Lama masak P4 (tekanan 0,008 bar) berbeda nyata dengan perlakuan P1, P2 dan P3. Lama masak pada pempek yang diberi perlakuan $\mathrm{P} 4$ adalah rerata sebesar 22,08 menit. Lama masak tersebut lebih lama bila dibandingkan dengan perlakuan lainnya. Penggunaan tekanan yang tinggi pada pemasakan dapat menghasilkan gelatinisasi yang homogen dan dapat menurunkan persentase butiran yang hancur (Bhattacharya, 1985; Baz et al., 1992).
Tabel 1. Nilai tekanan (P) dan lama pengeringan (L) terhadap lama masak pempek instan

\begin{tabular}{ccc}
\hline Perlakuan & $\begin{array}{c}\text { Lama masak*) } \\
\text { (menit) }\end{array}$ & Notasi**) \\
\hline P4 & 22,08 & $\mathrm{~A}$ \\
P1 & 17,50 & $\mathrm{~B}$ \\
P2 & 11,50 & $\mathrm{C}$ \\
P3 & 10,83 & $\mathrm{D}$ \\
L4 & 16,75 & $\mathrm{~A}$ \\
L1 & 15,92 & $\mathrm{~B}$ \\
L3 & 15,08 & $\mathrm{C}$ \\
L2 & 14,17 & $\mathrm{D}$ \\
\hline
\end{tabular}

Keterangan: P1=Tekanan 0,002 bar; P2=Tekanan 0,004 bar; P3=Tekanan 0,006 bar; P4=Tekanan 0,008 bar; L1=Waktu 38 jam; L2=Waktu 40 jam; L3=Waktu 42 jam; L4=Waktu 44 jam

*) : Hasil analisis (Data Primer)

**) : Angka-angka yang diikuti oleh huruf yang berbeda berarti berbeda nyata pada uji BNJD $\alpha=5 \%$

Perlakuan L4 (waktu 44 jam) berbeda nyata dengan perlakuan lainnya dengan rerata sebesar 16,75 menit. Lama masak tersebut lebih lama bila dibandingkan dengan perlakuan lainnya. Pempek instan tersebut kurang porous, lebih kering karena kadar air lebih rendah sehingga air dan panas yang masuk lebih lambat, sehingga membutuhkan waktu yang lebih lama agar pempek tersebut untuk dapat kembali seperti sermula. Perlakuan L4 (waktu 44 jam) berbeda nyata dengan perlakuan lainnya dan lama masaknya 16,75 menit. Perlakuan L4 lama masak lebih lama bila dibandingkan dengan perlakuan lainnya. Pempek lenjer basah yang direbus membutuhkan waktu sekitar 15-30 menit dan lama perebusan ini sangat tergantung dengan ukuran dan jenis pempeknya. Proses perebusan bertujuan agar pati mengalami proses gelatinisasi, sehingga granula pati mengembang dan proteinnya terdenaturasi. Pengembangan granula pati disebabkan oleh molekulmolekul air yang melakukan penetrasi ke dalam granula dan terperangkap dalam susunan molekul-molekul amilosa dan 
amilopektin. Pempek juga dapat dimasak dengan pengukusan pada suhu $80^{\circ} \mathrm{C}$ selama 20-30 menit.

\section{Densitas Pempek Instan}

Densitas atau massa jenis pempek instan merupakan suatu besaran kerapatan massa pempek instan yang dapat menentukan kemudahan air untuk masuk atau terehidrasi. Hasil analisis keragaman densitas diperoleh bahwa perlakuan tekanan memberikan pengaruh yang nyata terhadap densitas pempek lenjer instan, sedangkan perlakuan waktu dan interaksi memberikan pengaruh yang sangat nyata terhadap densitas pempek lenjer instan.

Densitas pempek instan seperti pada Tabel 2 menunjukkan bahwa perlakuan P4 (tekanan 0,008 bar) berbeda nyata dengan perlakuan P1, P3 dan P2. Densitas pada pempek yang diberi perlakuan $\mathrm{P} 4$ adalah sebesar $0,71 \mathrm{~g} / \mathrm{cm}^{3}$. Densitas tersebut lebih rendah bila dibandingkan dengan perlakuan lainnya. Pempek merupakan produk komposit, yaitu terdiri dari bahanbahan tepung tapioka, daging ikan gabus, air dan garam. Tepung tapioka salah satu faktor yang menyebabkan tingginya densitas pempek instan.

Perlakuan L4 (waktu 44 jam) berbeda tidak nyata dengan perlakuan L1, tetapi berbeda nyata dengan perlakuan L3 dan L2. Densitas pada pempek yang diberi perlakuan L2 adalah sebesar $0,75 \mathrm{~g} / \mathrm{cm}^{3}$. Densitas tersebut lebih tinggi bila dibandingkan dengan perlakuan lainnya. Pempek yang dilakuktaan freeze drying lebih lama yaitu selama 44 jam terjadi kerapatan yang lebih tinggi ditandai dengan dengan kadar air 2,73\% dan $\mathrm{a}_{\mathrm{w}}$ sebesar 0,15 lebih rendah dengan kadar air dan $\mathrm{a}_{\mathrm{w}}$ perlakuan lainnya.
Tabel 2. Nilai tekanan (P) dan lama pengeringan (L) terhadap densitas pempek instan

\begin{tabular}{ccc}
\hline Perlakuan & $\begin{array}{c}\text { Densitas* } \\
\left(\mathrm{g} / \mathrm{cm}^{3}\right)\end{array}$ & Notasi*) \\
\hline P2 & 0,75 & $\mathrm{a}$ \\
P3 & 0,74 & $\mathrm{a}$ \\
P1 & 0,73 & $\mathrm{a}$ \\
P4 & 0,71 & $\mathrm{~b}$ \\
L4 & 0,75 & $\mathrm{a}$ \\
L1 & 0,75 & $\mathrm{a}$ \\
L3 & 0,72 & $\mathrm{~b}$ \\
L2 & 0,71 & $\mathrm{~b}$ \\
\hline
\end{tabular}

Keterangan: P1=Tekanan 0,002 bar; P2=Tekanan 0,004 bar; P3=Tekanan 0,006 bar; P4=Tekanan 0,008 bar; L1=Waktu 38 jam; L2=Waktu 40 jam; L3=Waktu 42 jam; L4=Waktu 44 jam

*) : Hasil analisis (Data Primer)

**) : Angka-angka yang diikuti oleh huruf yang berbeda berarti berbeda nyata pada uji BNJD $\alpha=5 \%$

Densitas pempek instan akan turun dengan bertambahnya waktu L2 dan akan mulai naik lagi pada L3 dan L4, sehingga waktu bertambah maka densitas akan bertambah atau tinggi. Hal ini sesuai dengan hasil penelitian Bennamoun et al. (2008), bahwa semakin bertambahnya waktu, maka densitas $\left(\mathrm{kg} / \mathrm{m}^{3}\right)$ juga semakin menaik atau tinggi. Nilai densitas juga ditentukan kandungan zat gizi yang terdapat dalam bahan makanan seperti air, karbohidrat, lemak, protein dan kadar abu. Pempek mengandung karbohidrat berupa pati yaitu amilopektin $83 \%$ dan amilosa 17\% (Winarno, 2004). Koc et al. (2008) meyatakan bahwa densitas dapat ditentukan oleh volume dan massa dari produk makanan tersebut. Pempek instan yang pengolahannya dengan metode freeze drying sedikit sekali mengalami perubahan volume, namun lebih banyak mengalami perubahan massa, maka densitas pempek instan rendah. 


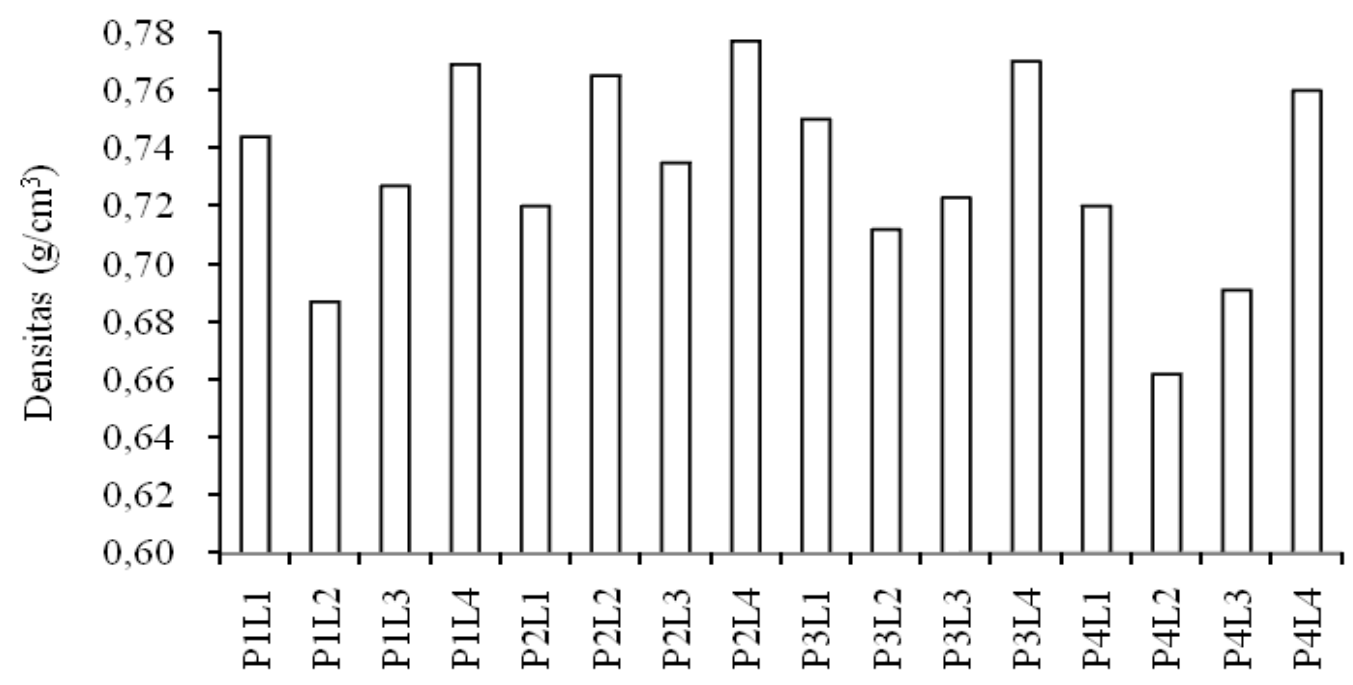

Kombinasi perlakuan

Gambar 1. Densitas pempek instan dilihat dari kombinasi perlakuan (PL)

Densitas pempek instan pada perlakuan P2L4 (tekanan 0,004 bar dan waktu 44 jam) pada Gambar 1 sebesar 0,78 lebih tinggi bila dibandingkan dengan perlakuan lainnya. Waktu sangat mempengaruhi tinggi densitas pempek instan, sehingga sekali mengalami perubahan massa pempek instan, sedangkan volumenya sedikit sekali pengalami perubahan.

\section{Kecerahan Warna (Lightness) Pempek Instan}

Perlakuan tekanan, waktu dan interaksi memberikan pengaruh yang sangat nyata terhadap kecerahan warna pempek lenjer instan. Kecerahan warna pempek instan (Tabel 3) menunjukkan bahwa perlakuan P1 (tekanan 0.002 bar) berbeda nyata dengan perlakuan P2, P3 dan P4. Kecerahan warna pada pempek yang diberi perlakuan P1 adalah sebesar 83,01. Kecerahan warna tersebut lebih tinggi bila dibandingkan dengan perlakuan lainnya. Kecerahan warna perlakuan L4 (waktu 44 jam) seperti pada Tabel 3 berbeda nyata dengan perlakuan L3, L2 dan L1. Kecerahan warna pada pempek yang diberi perlakuan T4 adalah sebesar 84,62 .

Tabel 3. Nilai tekanan (P) dan lama pengeringan (L) terhadap kecerahan warna pempek instan

\begin{tabular}{ccc}
\hline Perlakuan & $\begin{array}{c}\text { Warna } \\
\text { (Lightnees) }^{*}\end{array}$ & Notasi** $^{* *}$ \\
\hline P1 & 83,01 & $\mathrm{a}$ \\
P2 & 82,21 & $\mathrm{~b}$ \\
P3 & 80,14 & $\mathrm{c}$ \\
P4 & 79,94 & $\mathrm{c}$ \\
L4 & 84.62 & $\mathrm{a}$ \\
L3 & 81,83 & $\mathrm{~b}$ \\
L2 & 80,67 & $\mathrm{c}$ \\
L1 & 78,19 & $\mathrm{~d}$ \\
\hline
\end{tabular}

Keterangan: P1=Tekanan 0,002 bar; P2=Tekanan 0,004 bar; P3=Tekanan 0,006 bar; P4=Tekanan 0,008 bar; L1=Waktu 38 jam; L2=Waktu 40 jam; L3=Waktu 42 jam; L4=Waktu 44 jam

*) : Hasil analisis (Data Primer)

**) : Angka-angka yang diikuti oleh huruf yang berbeda berarti berbeda nyata pada uji BNJD $\alpha=5 \%$

Kecerahan warna pempek instan pada perlakuan P2L4 (tekanan 0,004 bar dan waktu 44 jam) pada Gambar 2 


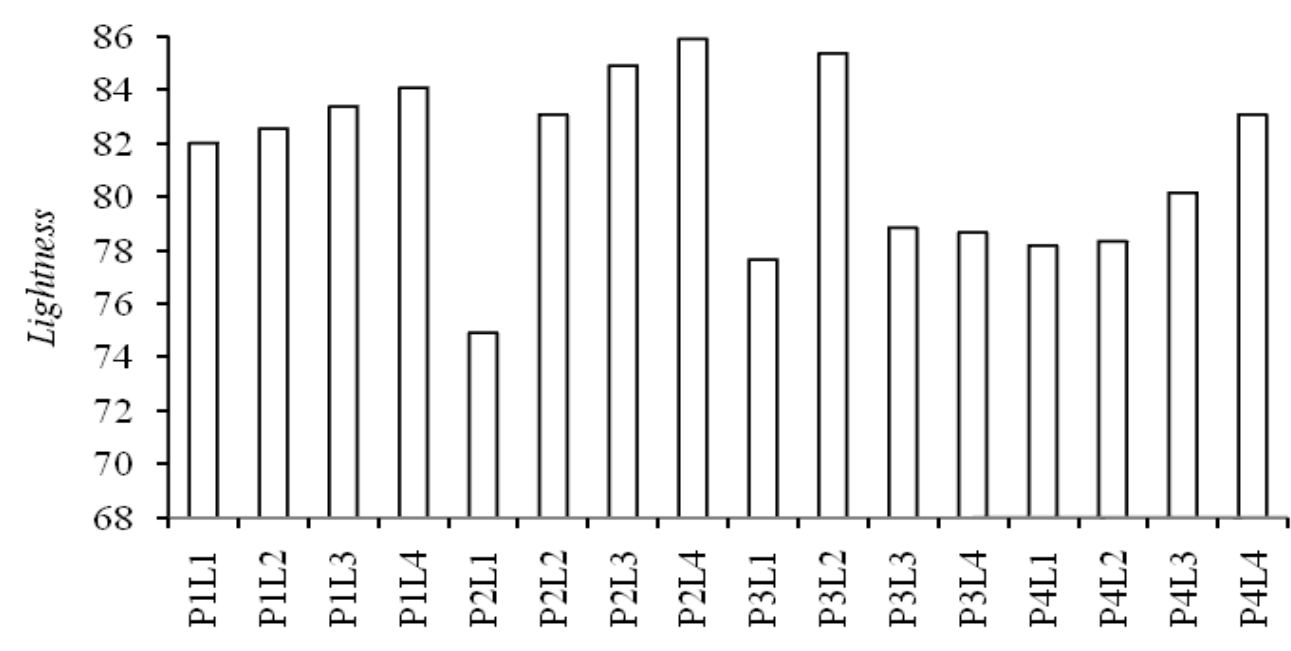

Komb inasi perlakuan

Gambar 2. Lightness (kecerahan warna) pempek instan dilihat dari kombinasi perlakuan (PL)

sebesar 85,92 lebih tinggi bila dibandingkan dengan perlakuan lainnya. Kecerahan warna pempek instan karena pati berwarna putih, berbentuk serbuk bukan kristal yang tidak larut dalam air dingin, dan tidak mempunyai rasa manis. Hidrolisis pati dapat dilakukan oleh asam atau enzim (Gaman dan Sherrington, 1992). Warna produk pangan kering sangat dipengaruhi oleh suhu pengeringan. Dari hasil penelitian Jokic et al. (2009) terhadap asparagus kering, diperoleh bahan untuk sampel kering, semakin tinggi suhu atau semakin kecil suhu dibawah nol, maka tingkat lightness $\left(\mathrm{L}^{*}\right)$ semakin besar, untuk pengeringan beku mengarah ke green color, sedangkan yang lain yellow color. Warna yang lebih baik pada metode pengeringan beku pada suhu minimal $10^{\circ} \mathrm{C}$.

\section{KESIMPULAN}

Pempek lenjer basah berbentuk tabung ukuran tinggi $3 \mathrm{~cm}$ dan diameter 4 $\mathrm{cm}$ dapat dilakukan pengolahan menjadi pempek instan dengan metode pengeringann freeze drying dengan pengaturan tekanan dan waktu. Perlakuan tekanan dan waktu berpengaruh sangat nyata terhadap lama masak, densitas, dan lightness, serta perlakuan kombinasi perlakuan tekanan dan waktu berpengaruh sangat nyata terhadap densitas dan lightness pempek instan. Pempek instan yang diproses pada tekanan 0,006 bar (P3) menghasilkan lama masak lebih singkat yaitu 10,83 menit dan pada perlakuan L2 yaitu 14,17 menit dari perlakuan lainnya. Pempek instan pada kombinasi perlakuan P3L2 memiliki densitas yang rendah yaitu $0,71 \mathrm{~g} / \mathrm{cm}^{3}$ dan tingkat kecerahan warna (lightness) hampir ke putih sebesar 85,38.

\section{UCAPAN TERIMA KASIH}

$$
\begin{aligned}
& \text { Ucapan terima kasih ditujukan } \\
& \text { kepada } \text { Rektor Universitas } \\
& \text { Muhammadiyah Palembang yang telah } \\
& \text { mendukung secara finansial terlaksananya } \\
& \text { penelitian yang berjudul pengembangan } \\
& \text { pempek instan dengan metode freeze } \\
& \text { drying tahun 2017. }
\end{aligned}
$$

\section{DAFTAR PUSTAKA}

Alhanannasir A, Rejo A, Saputra D dan Priyanto G. 2017. Karakteritik Pempek Instan dengan Pengolahan Pengeringan oven dan freeze drying. Prosiding Seminar Nasional PATPI. Fakultas Pertanian Universitas Lampung, pp: 191-200. 
Baz, A.A., Hsu J.Y., Scoville E., 1992. Preparation of quick cooking rice. US Patent 5.089.281.

Bennamoun, L dan Belhamri, A., 2008. Mathematical description of heat and mass transfer during deep bed drying: effect of product shrinkage on bed porosity. Applied Thermal Engineering, 28 (17): 2236-2244.

Bonazzi, C., and Dumoulin E. 2011. Quality Changes in Food Materials as Influenced by Drying Process. Modern Drying Technology volume 3. WilleyVCH Verlag GmbH \& Co.KGaA.

Chakraborty N, Chakraborty R, and Saha AK. 2016. Dehydration of kiwi of fruit (Actinidia deliciosa) by consecutive osmotic dehydration and freeze-drying. Indian Journal of Science and Technology, 9 (28): 1-8

deMan, JM. 1999. Principles of Food Chemestry. Edition 3. Aspen Publisher, Inc. Gaithersburg, Maryland

Desmorieux H, Madiouli J, Herraud C and Mouaziz H.C. 2010. Effects of size and form of Arthrospira spirulina biomass on the shrinkage and porosity during drying. Journal of Food Engineering, 100 (4): 585-595.

Dissa, A.O., Desmorieux, H., Savadogo, P.W., and Segda Band Koulidiati, J. 2010. Shrinkage, porosity and density behavior during convective drying of spirulina. Journal of Food Engineering, 97 (3): 410-418.

Gaman, P.M dan Sherrington., K.B., 1992. Ilmu Pangan Pengantar Ilmu Pangan, Nutrisidan Mikrobiologi. Unversitas Gajah Mada Press, Yogyakarta.

Haryadi, P. 2013. Freeze drying Technology: For better quality \& flavor of dried products. Foodreview Indonesia, 8 (2): 52-57.

Hao, J.H., Chen, Q., and Hu, K. 2016. Porosity distribution optimization of insulation materials by the variational method. International Journal of Heat and Mass Transfer, 92 (1): 1-7.
Jokic, S., Mujic, I., Martinov, M., Velic, D., Bilic Mand Lukinac, J. 2009. Influence of drying procedure on colour an rehydration characteristic of wild asparagus. Journal of Food Science, 27 (3): 171-177.

Koc, B, I., Eren dan Ertekin, F.K. 2007. Modelling bulk density, porosity and shrinkage of quince during: The effect of drying method. Journal of Food Engineering, 85 (3): 340-349.

Krokida M.K, Zogzas, N.P., and Maroulis ZB. 1997. Modelling shrinkage and porosity during vacuum dehydration. International Journal of Food Science and Technology, 32 (6): 445-458.

Krokida, M.K., Oreopoulou, V., and Maroulis, Z.B. 2000. Effect of drying conditions on shrinkage and porosity of fried potatoes. Journal of Food Engineering, 43 (3): 147-154.

Koc, B., Eren, I., and Ertekin, F.K. 2008. Modelling bulk density, porosity and shrinkage of quince during: The effect of drying method. Journal of Food Engineering, 85 (3): 340-349.

Khalloufi, S., Rivera, C.L. and Bongers, P. 2009. Theoretical model and its experimental validation to predict porosity as a function of shrinkage and collaps during drying. Food Research International, 42 (8): 1122-1130.

Karneta, R., Rejo, A., Priyanto, G., and Pambayun, R. 2013. Difusivitas panas dan umur simpan pempek lenjer. Jurnal Keteknikan Pertanian, 27 (2): 131-141.

Karneta R., Rejo A, Priyanto G and Pambayun R.2013. Perubahan nilai gizi pempek lenjer selama perebusan. Jurnal Pembangunan Manusia, 7 (2): 52-64.

Liu, G., Chen, J., Liu, M., and Wan, X. 2012. Shrinkage, porosity and density behavior during convective drying of bio-porous material. Procedia Engineering, 31 (4): 634-640. 
Martynenko A. 2008. The system of correlation between moisture, shrinkage, density, and porosity. Drying Technology, 26 (1): 1947-1500.

Mayor, L., Moreira, R., and Sereno, A.M. 2011. Shrinkage, density, porosity and shape changes during dehydration of pumpkin (Cucurbita pepo L.) fruits. Journal of Food Engineering, 103 (1): 29-37.

Madiouli, J., Sghaier, J., Lecomte, D., and Sammouda, H. 2012. Determination of porosity change from shrinkage curves during drying of food material. Food and Bioproducts Processing, 90 (1): 43-51.

Ratti, C. 2013. Freeze drying for Food Powder Production.Handbook of Food Powders Processes and Properties. Woodhead Publishing.

Zogzas, N.P., Maroulis, Z.B., and Kouris, D.M. 1994. Densities, shrinkage and poposity of some vegetables during air drying. Drying Technology, 12 (7): 1653-1666.

Winarno, F.G. 2004. Kimia Pangan dan Gizi. Gramedia Pustaka Utama, Jakarta. 